\title{
usm

\section{O planejamento docente e a avaliação: uma reflexão sobre os seus reflexos na repetência escolar dos alunos das escolas do I Ciclo em Cabinda/Angola}

\author{
The planning of teacher and evaluation: a reflection on their \\ reflexes in the school repetition of the pupils of the schools of the $1^{\text {st }}$ \\ Cycle in Cabinda/Angola
}

Fernando Abel Mavungo

Docente na Universidade Onze de Novembro, República de Angola, Cabinda, Zaire. fmavngo@yahoo.com - https://orcid.org/0000-0002-4821-3764

Recebido em 08 de julho de 2019

Aprovado em 30 de setembro de 2019

Publicado em 20 de novembro de 2019

\section{RESUMO}

Este artigo versa sobre o planejamento docente, a avaliação e a repetência escolar, ecoando as preocupações da sociedade cabindense, concernentes ao elevado número de alunos que reprovam de classe. $O$ objetivo que 0 norteia busca a partir da análise das publicações relacionadas com essas três categorias, refletir sobre o que é dito e o que é feito em suas ocorrências nas escolas do I Ciclo em Cabinda e sobre os seus reflexos na realidade escolar dos alunos. Trata-se de uma pesquisa qualitativa bibliográfica, cujos objetos de análise e reflexão foram os documentos oficiais do Ministério da Educação, livros e artigos produzidos por pesquisadores locais e estrangeiros, assim como alguns trabalhos feitos por professores que lecionam nesse ciclo. Neste estudo ficou notório que, embora as pesquisas mostram a relevância desses instrumentos no êxito do processo pedagógico, os mesmos no cotidiano de muitos professores dessas escolas não passam de simples formalidade, ao carecer das ações concretas que situam os seus alunos no cerne das atividades que são planejadas, executadas e avaliadas nas salas de aulas, tendo-os como sujeitos concretos. Reconhece-se que para um maior afloramento das questões que foram levantadas nessa pesquisa, precisa-se de mais estudos, visando subsidiar a atuação desses professores nos seus planejamentos e nas suas avaliações. Neste estudo concluiu-se que a qualidade do planejamento diário dos professores do I ciclo tem reflexos nos resultados das avaliações dos alunos e incidem nos índices da repetência escolar que são observados nessas escolas.

Palavras-chave: Planejamento docente; Avaliação; Repetência escolar. 


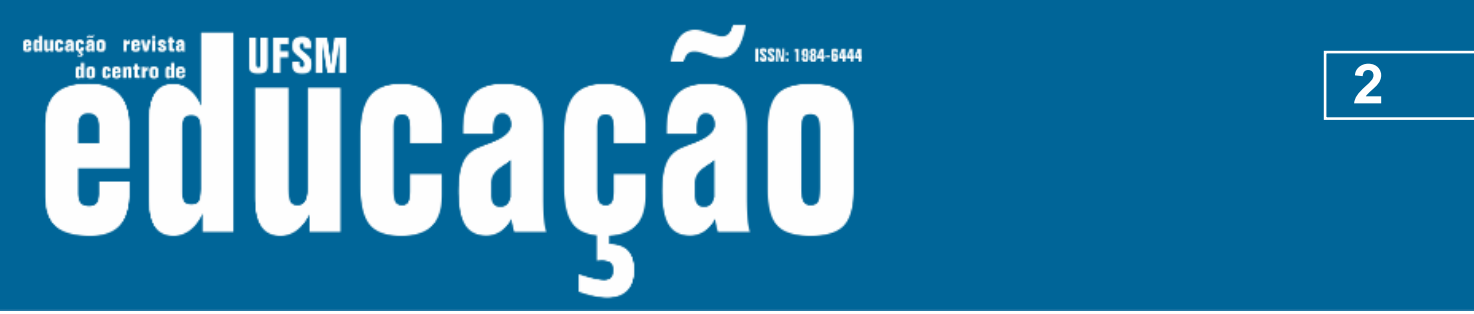

ISSN: 1984-6444 | http://dx.doi.org/10.5902/1984644438951

\section{ABSTRACT}

This study has as focus the planning of teachers, evaluation and school repetition, echoing the concerns of Angolan society in general and Cabindan in particular, regarding the high number of students which suffer the problem of school repetition. Its objective seek from the analysis of the bibliography related to these three categories to reflect on what is said and what is done in the schools of the $1{ }^{\text {st }}$ cycle in Cabinda and its effects on the students' school reality. Therefore, it is a qualitative research, based on the bibliographical approach, having as objects of analysis and reflection the official documents of ministry of education, books and articles produced by local and foreign researchers and some works done by teachers who teach in this cycle. It is understood that although research and pedagogical practices show the importance of these pedagogical tools, the same in the daily life of many teachers it is no more than a simple bureaucratic formality, lacking the concrete actions that place the student at the heart of the activities that are planned, executed and evaluated in the classroom, taking him as a concret person. In conclusion, it can be argued that studies involving this school problem should continue, seeking how to improve the pedagogical doing of teachers. However, it appears that the quality of the teacher's daily planning has reflexes in the results of the students' evaluations and affects the school repetition rates that are observed in these schools in Cabinda. Keywords: Planning of teacher; Evaluation; School repetition.

\section{Introdução}

O presente artigo gira em torno do planejamento docente, da avaliação e da repetência escolar, três realidades que se cruzam entre si nos espaços escolares, cujos intervenientes principais são os professores e os alunos. O mesmo tem por escopo oferecer uma reflexão sobre essas dimensões que transpassam a realidade das nossas escolas, afetando tanto a qualidade do que ali acontece, quanto a qualidade da inserção dos alunos na sociedade, no bojo do fazer pedagógico dos professores.

As questões que o nortearam prendem-se tendo em conta as diferentes vozes que hoje se levantam na sociedade angolana, à luz dos resultados que são tornados públicos nos diferentes espaços escolares do ensino público, particularmente no I Ciclo. Soma-se a isso, os resultados dos concursos de acesso ao primeiro emprego, 
ISSN: 1984-6444 | http://dx.doi.org/10.5902/1984644438951

dos exames de acesso às universidades, os quais, não tem sido abonatório para o governo, o seu ministério de tutela e a sociedade no geral.

Entre essas vozes, por um lado, destaca-se a dos indivíduos que não poupam as suas críticas à escola e ao papel dos professores. Por outro, a de aqueles que culpam a qualidade dos instrumentos de avaliação que são aplicados nesses concursos, que ao invés de se cingirem nos saberes pertinentes ao tipo de profissão, seus princípios e regras de conduta, ou seja, a deontologia concreta da profissão, priorizam os saberes de cunho geral na seleção dos médicos, enfermeiros, professores, juízes.

Neste contexto, trata-se de críticas sociais legítimas que, por sinal, devem encorajar o governo, o seu ministério de tutela, os gestores escolares, os professores e os estudiosos a uma reflexão séria, como forma de se pensar e repensar melhor a contribuição que a sociedade pode esperar da escola, sendo este um espaço de aquisição de capacidades para todos os alunos. Contudo, esclarecese que o olhar neste texto se foca para o que ocorre nas escolas e aos papéis que são desempenhados pelos professores e alunos, fora e dentro das salas de aulas.

Em face disso, é importante salientar que a contribuição da escola para com a sociedade tem entre os seus principais eixos, o professor. Esse sim, que no seu agir comprometido se embasa nas suas leituras e visões do mundo que o rodeia, assumindo-se como obreiro na construção de um mundo melhor, conscientizando, empoderando todos os seus educandos a fazer frente aos seus múltiplos desafios do presente e do futuro.

Diante disso, o trabalho de planejamento e a prática pedagógica do professor nos espaços escolares aparecem como sendo as imagens que revelam a verdadeira identidade do professor, tornando deste modo perceptível não só o cotidiano do mesmo, como também a contribuição da escola em prol da solução dos problemas com que a sociedade se depara.

Paradoxalmente, embora as pesquisas fornecem ideias claras sobre a necessidade de um planejamento docente sério, que se traduz em processos educativos significativos, as práticas pedagógicas dos professores que são observadas in loco, particularmente em Cabinda, muitas vezes parecem resumir-se 


\section{(1) Lusm \\ ISSN: 1884-6444

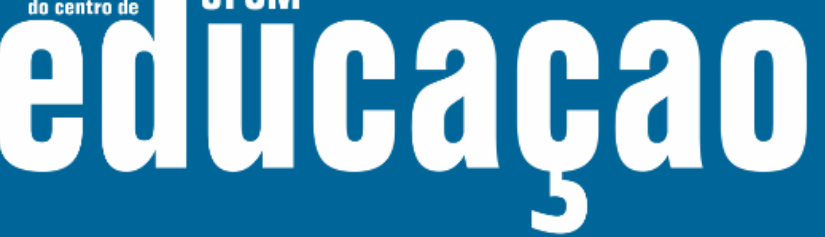

ISSN: 1984-6444 | http://dx.doi.org/10.5902/1984644438951

em banalidades. Os planos de aulas dos professores parecem não revelar sintonia, entre o que é planejado e o que é executado na sala de aula, refletindo as particularidades dos alunos, do contexto sociocultural do país e de um ideal pedagógico crítico, sinalando as várias atividades que os mesmos conduzem na sala de aula.

Para o que se entende por planejamento, numa percepção inicial Luckesi (2006, p. 115) nos lembra que, "os fins, sem a ação construtiva, adquirem a característica de fantasias inócuas; a ação aleatória, sem fins definidos, desemboca no ativismo". Da ideia desse autor, pode-se inferir que a ânsia por se obter resultados satisfatórios levam o homem a necessidade de planejar e avaliar as suas ações com seriedade como forma de potenciá-los e evitar-se o desperdício de recursos que emana das ações improvisadas.

Com essa visão, o planejamento docente, a avaliação e a repetência escolar parecem constituir um trio, uma encruzilhada que se apresenta na escola, podendo, a partir do tipo de planejamento feito pelo professor, ensombrecer ou dar o brilho aos resultados. Contudo, para a obtenção de excelentes resultados impõe-se, ineludivelmente, a necessidade de se reformular e repensar os modos de fazer e de agir dos professores, partindo desde o próprio momento do planejamento das suas ações pedagógicas.

Como que desafiando essa ideia, Delors (1996, p. 12), referindo-se a escola e a educação, nos lembra que, "a educação tem a missão de permitir a todos sem exceção fazer frutificar todos os seus talentos e todas as suas capacidades de criação, o que implica que cada um possa realizar o seu projeto pessoal".

O papel da escola, conforme destaca esse pesquisador, impõe aos professores e investigadores uma indagação e reflexão perspicaz, na perspectiva de, por um lado, enxergar e perceber o quanto as ações que são planejadas e executadas pelos professores nas salas de aulas conlevam à formação e o desenvolvimento de capacidades em todos alunos. Por outro, oferecer as melhores alternativas que aproximam as nossas escolas do seu desiderato histórico.

Nessa linha de explicitação, este estudo parte da premissa de que o planejamento do professor ao prever e arquitetar todas as ocorrências que se 


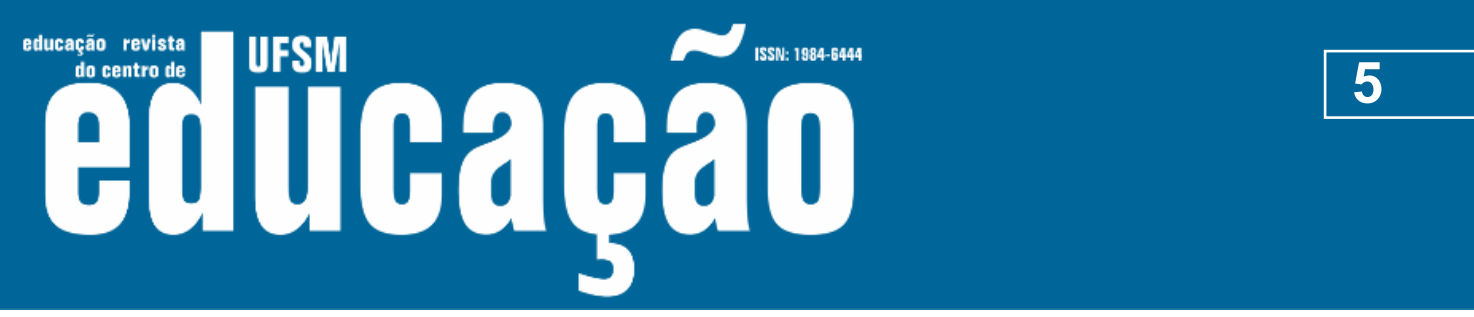

ISSN: 1984-6444 | http://dx.doi.org/10.5902/1984644438951

produzem no ambiente de construção dos saberes na sala de aula, ainda que se espere flexibilidade durante a sua execução, tem reflexos na qualidade do processo de ensino e aprendizagem, assim como também, tem impactos nos índices de repetência escolar que são vivenciados nas escolas.

Portanto, é de salientar que, este estudo de natureza qualitativa assenta-se no enfoque bibliográfico. Neste contexto, documentos oficiais do Ministério da Educação tais como os programas, manuais de apoio ao sistema de avaliação das aprendizagens, livros e artigos de autoria de pesquisadores locais e estrangeiros, assim como trabalhos produzidos por professores que lecionam nesse ciclo se constituíram no principal material objeto da análise e reflexão.

Assim sendo, trata-se de um estudo que se ajusta nos moldes qualitativos, buscando, conforme ressalta Angrosino (2009):

\begin{abstract}
Esmiuçar a forma como as pessoas constroem o mundo à sua volta, o que estão fazendo ou o que está lhes acontecendo em termos que tenham sentido e que ofereçam uma visão rica. As interações e os documentos são considerados como formas de constituir, de forma conjunta (ou conflituosa), processos e artefatos sociais (ANGROSINO, 2009, p. 8).
\end{abstract}

\title{
Discutindo as visões conceituais sobre o termo planejamento docente.
}

Antes de falar sobre o planejamento docente, a avaliação e seus reflexos na repetência escolar, é imperativo se perguntar ainda, o que é o planejamento docente?

Em primeiro lugar, deve-se esclarecer que o planejamento é uma atividade que perpassa todas as áreas da vida do homem. Em face disso, o mesmo na literatura admite várias acepções. No entanto, neste estudo essa expressão é restrita as atividades de previsão e de escolha do professor, que resultam no seu planejamento de ensino e mais, concretamente, no seu planejamento de aula ou plano diário.

Assim, apesar da natureza multiforme desse termo, que a nível do processo de ensino e aprendizagem aglutina expressões tais como planejamento do sistema 


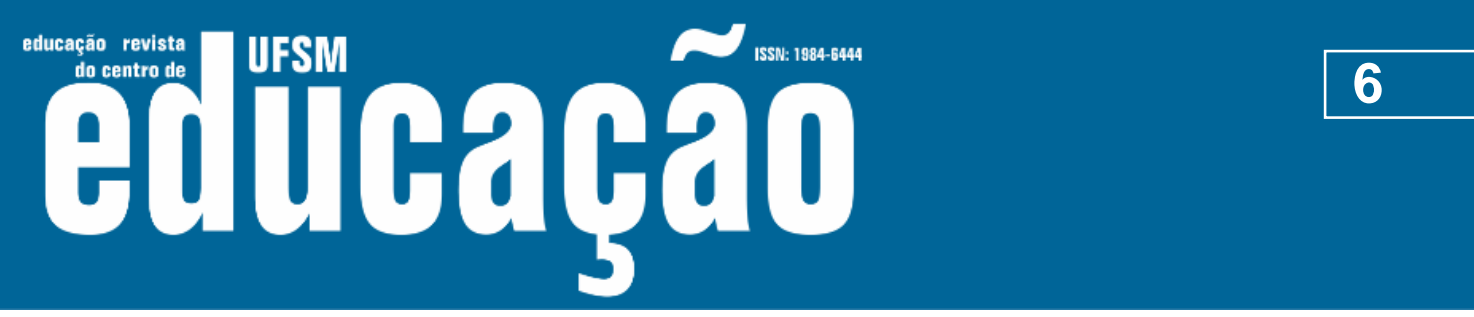

ISSN: 1984-6444 | http://dx.doi.org/10.5902/1984644438951

educacional; planejamento escolar; planejamento de curso; planejamento didático ou de ensino; planejamento curricular, o planejamento de aula que aqui designamos por planejamento docente é o foco deste estudo.

Neste contexto, indo ao encontro da questão que foi levantada, Holanda (1977) percebe a expressão planejamento como a atividade, através da qual, se coloca em prática o acervo de conhecimentos, objetivando a escolha das mais adequadas e racionais decisões em face de como atuar com precisão no futuro.

Contudo, para Haidt (2004), uma pesquisadora no campo de educação, o planejamento implica atentar-se à realidade, refletir sobre ela com objetividade e adiantar-se com os seus resultados ao escolher as alternativas de atuação mais pertinentes.

Para Turra et al. (1975) apud Luckesi (2006, p.122) "é o processo de tomada de decisões bem informadas que visam a racionalização das atividades do professor e do aluno, na situação ensino-aprendizagem, possibilitando melhores resultados e, em consequência, maior produtividade". No entanto, para Libâneo (1994, p. 222), não é mais do que "um processo de racionalização, organização e coordenação da ação docente, articulando a atividade escolar e a problemática do contexto social."

Tocante especificamente ao planejamento de aula, Haidt (2004) ainda enfatiza a necessidade de se definir previamente, entre vários elementos: os objetivos imediatos que devem ser alcançados durante a aula; os conceitos, as habilidades, hábitos e atitudes associados a esses conceitos; os procedimentos e as estratégias metodológicas que norteiam a atuação do professor em seu papel de orientador, e dos alunos, no seu papel de construtores ativos dos saberes ensinados; os recursos didáticos nos quais se assentam o aprendizado dos alunos e a previsão explícita das formas de avaliação das atividades dos discentes.

A mesma autora ressalta:

É a sequência de tudo o que vai ser desenvolvido em um dia letivo. A sistematização de todas as atividades que se desenvolvem no período de tempo em que o professor e o aluno interagem, numa dinâmica de ensino e aprendizagem (HAIDT, 2004, p. 103).

Coerente com as ideias desses autores, temos o texto da Secretaria de Estado de Educação e Cultura de Piauí (2013), que na sua aproximação às visões 


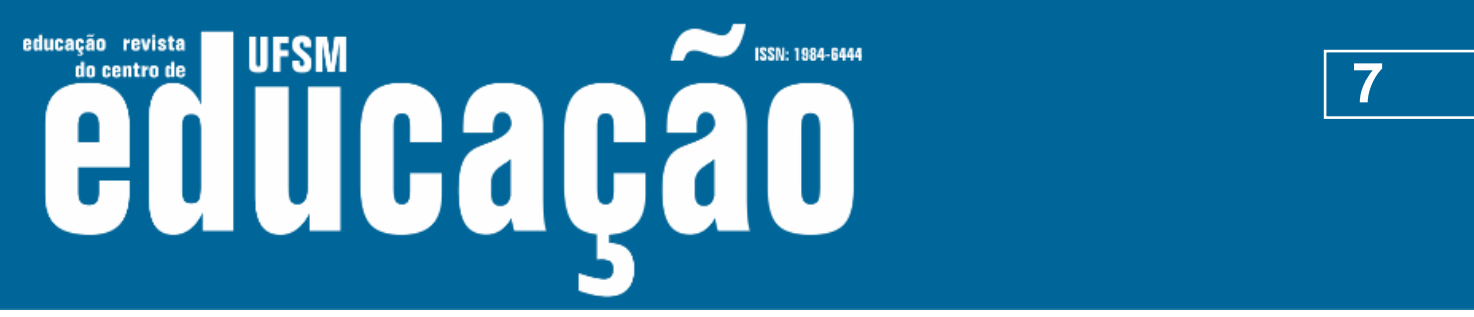

ISSN: 1984-6444 | http://dx.doi.org/10.5902/1984644438951

da matriz nacional da educacional do Brasil, explicita a principal missão da escola nesse espaço, seu engajamento no asseguramento do acesso, da permanência e da qualidade das aprendizagens em prol da formação da consciência cidadã dos alunos.

Assim, nesse documento são explicitados os padrões básicos de aprendizagem das várias disciplinas, nos quais, os conteúdos, as metodologias e as formas de avaliação para cada disciplina e classe ocupam as posições de destaque, cuja operacionalização não se retira a autonomia do professor.

Concernente a parte metodológica e a avaliação, vale reconhecer que, nessas diretrizes a ênfase é dada para utilização de estratégias de ensino problematizadoras, empregando as vias dedutivas e indutivas. Portanto, essas estratégias se assentam no cumprimento de várias fases, tais como: a fase de problematização e a da instrumentalização (fase da construção dos novos saberes), assente na solução dos problemas que são levantados no início da aula (PIAUí, 2013).

Nessas diretrizes a avaliação inclui, entre vários aspectos, os saberes disciplinares, representados em gráficos, tabelas, mapas, textos; as atitudes, o grau de independência, o companheirismo, o respeito às opiniões dos colegas.

Já no contexto local do nosso sistema educativo, as diretrizes curriculares as encontramos nos diferentes programas das disciplinas que são lecionadas nessas escolas, por exemplo, Matemática, História, Biologia, Química etc.

Tocante ao ensino da Biologia, as mesmas são identificadas nos Programas dessa disciplina no I e II Ciclos, nomeadamente na $7^{\underline{a}}$, $8^{\underline{a}}$ e $9^{\underline{a}}$ classes e na $10^{\underline{a}}, 11^{\underline{a}}$ e $12^{\mathrm{a}}$ classes, explicitando os objetivos gerais e específicos, os conteúdos dos diferentes temas e as habilidades a serem formadas em cada trimestre, as visões metodológicas gerais assim como o sistema de avaliações.

Concernente ao planejamento de aula, a título de exemplo, aqui apresentamos alguns registros de planos de aulas que foram elaborados por professores de biologia de algumas escolas do I Ciclo da cidade de Cabinda (outros em Anexos), nos quais a introdução, o desenvolvimento e as conclusões aparecem como momentos marcantes nessas aulas. 


\section{T=1 ursm

ISSN: 1984-6444 | http://dx.doi.org/10.5902/1984644438951

"Plano de aula

Escola:

Professor:

Disciplina: Biologia

Classe: 9aㅗ classe/ Regular

Tema: Organização das plantas.

Subtema: Estrutura e função dos órgãos vegetais. A folha.

Objetivo específico: identificar as estruturas que compõem a folha mediante a observação de um objeto natural a nível reprodutivo.

Método: expositivo, explicativo e elaboração conjunta.

Meio de ensino: quadro, giz, apagador, objeto natural e fascículo.

Introdução

- Controle das condições da sala de aula, marcação das presenças, correção tarefa.

- Asseguramento do nível de partida.

- Quais são as partes que podemos identificar numa folha?

Desenvolvimento

- Por meio dos objetos a serem ilustrados, efetua-se questões aos alunos e esclarecer em função das respostas a serem dadas pelos alunos.

Conclusões

- Identifique no quadro as estruturas de uma folha.

Tarefa

- Identificar as estruturas de uma folha dicotiledônea vista ao MOC pag. 84 Manual de Biologia 9a classe".

Enfim, essas indicações sobre o planejamento docente proporcionam-nos um certo entendimento sobre a noção de planejamento que é advogado tanto nas diretrizes curriculares de Brasil quanto do sistema educativo Angolano, que em nosso ver, coadunam e compartilham, de certa forma, com a visão de planejamento que é defendido por muitos autores Haidt (2004), Luckesi (2006), Libâneo (1994), entre outros. 


\section{N

ISSN: 1984-6444 | http://dx.doi.org/10.5902/1984644438951

Portanto, essa percepção de planejamento docente revela os condicionantes técnicos procedimentais que encerram a elaboração de planos de aula ao perfilar-se pela dinamização e operacionalização racional dos elementos que constam nas diretrizes curriculares, nos planejamentos didáticos e de aula, em particular, os objetivos e os conteúdos.

Contudo, essas visões de planejamento docente parecem ocultar a essência humana do professor e do aluno ao desprover-se do seu carácter político e social. Coerente com essa ideia, Luckesi (2006), olhando criticamente as visões dos diferentes planejamentos do ensino e das outras áreas do saber que são apresentados nos manuais e na literatura, chama atenção, sugerindo que o planejamento independentemente da sua tipologia e da área onde é aplicado, deve ajustar-se aos marcos das suas finalidades político-sociais.

Assim, em nosso ver, o planejamento longe de revestir-se apenas de procedimentos técnicos que revelam no papel a bagagem dos saberes docentes do professor, o mesmo acima de tudo, deve retratar para além da identidade do docente, a sua própria visão política- social crítica sobre o contexto que o rodeia.

Com esse pressuposto, o planejamento do trabalho diário do professor deve emergir do contexto vivido pelos alunos, na previsão das suas dificuldades, suas necessidades, seus recursos, embasados nos conteúdos, nas estratégias, nas situações conflitivas e dialógicas que conformam as alternativas de atuação privilegiadas pelo professor.

Tomando isso em conta, o planejamento docente oferece visões que trazem à tona o nível de comprometimento do professor em face do seu papel crítico para com a escola, a sociedade e o próprio aluno. E, por essa razão, o mesmo deixa transparecer os sentidos e significados que o professor atribui à avaliação formativa, assim como as suas considerações, relativamente a problemática da repetência escolar do aluno.

Desta forma, o planejamento docente não deve ser encarado apenas na perspectiva de o professor refletir, prever e projetar o cumprimento da sequência dos conteúdos do seu programa e avaliar o grau do seu cumprimento, partindo das orientações oferecidas nos programas curriculares. Mas, sobretudo, que o professor 
ISSN: 1984-6444 | http://dx.doi.org/10.5902/1984644438951

ao determinar os fins, as ações e os recursos com que conta, as suas escolhas desemboquem na construção de sentidos e significados para cada um dos alunos do coletivo da turma ou da escola, servindo isso de base para a formação da personalidade e da cidadania de cada um dos seus educandos.

É com esse entendimento que vemos o planejamento docente e compartilhamos o pensamento de Mavungo (2014), ao ressaltar que:

O planejamento deve ser repensado e ser visto como um recurso para a organização do processo de ensino e aprendizagem com vista a dar atenção às metas previamente concebidas, envolvendo a previsão dos resultados esperados assim como os meios para alcançá-los, tendo atenção à realidade sociocultural (MAVUNGO, 2014, p.41).

É pertinente com isso ressaltar que, o planejamento docente que emerge da realidade sociocultural, "não é neutro, mas ideologicamente comprometido (LUCKESI 2006, p.117). Neste sentido, o planejamento docente, para além do mais, deve levar em conta a realidade das nossas escolas, desde o ponto de vista da qualidade dos recursos, da infraestrutura, do contexto político pelo que passa o país, permeado pela necessidade da emancipação da mulher, da inclusão social e do combate às desigualdades sociais; da origem humilde da grande maioria dos nossos alunos, seu capital, seu histórico de repetência escolar, forjado numa visão crítica que conlevam a mudança de paradigmas.

Com isso, cabe perguntar, que relação existe entre o planejamento docente e a avaliação? O que é dito da avaliação na literatura, nos documentos oficiais e no contexto das escolas do I Ciclo e que relação têm com a repetência escolar nessas escolas?

\section{O planejamento docente e a avaliação: sua correlação no processo de ensino e aprendizagem.}

$\mathrm{Na}$ tentativa de se encontrar respostas a essas questões é imperativo começar afirmando que, tal como é onipresente e pertinente o planejamento nas mais distintas dimensões da vida humana, também o é a avaliação. Ou seja, o planejamento e a avaliação se encontram, se reencontram e se cruzam, permeando 


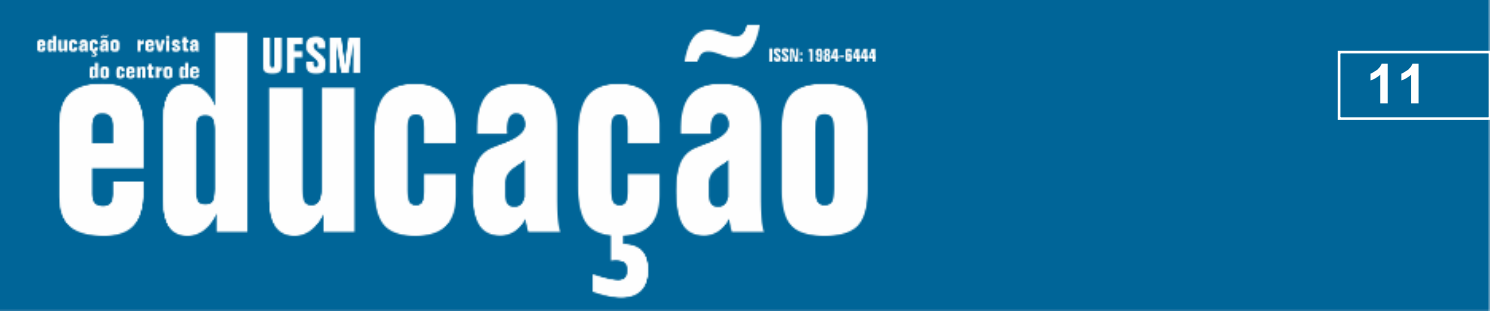

ISSN: 1984-6444 | http://dx.doi.org/10.5902/1984644438951

a vida do homem, porque ambos constituem momentos indispensáveis do ser humano na luta pela sua sobrevivência, na melhoria das suas condições de vida.

Portanto, o homem sendo um ser histórico e social é dotado de capacidades para traçar os caminhos que o conduzem aos seus resultados almejados. Para o efeito, define os seus objetivos, determina as atividades, as ações concretas e os recursos que o levam a sua materialização e passo a passo certifica-se da coerência dos resultados que o nortearam, desde o começo ao fim.

Diante disso, cabe reconhecer que não existe planejamento docente sem objetivos, nem resultados do planejamento sem a avaliação. Dito de outro modo, os mesmos objetivos que permeiam a elaboração de planos de aulas também norteiam a execução das ações na sala de aula, servindo assim como elementos essenciais para se estabelecer os critérios de verificação dos resultados, através da avaliação.

Sendo assim, a avaliação emerge do planejamento docente e seus resultados são o reflexo da qualidade do mesmo, revelando a velha máxima "tal árvore, tal fruto". Pois, os objetivos e a busca por melhores resultados leva o homem a planejar as suas ações e avaliar as mesmas como forma de aproximar e estimar a relação entre os resultados obtidos da sua execução às metas previamente estabelecidas no planejamento.

Desta forma, a avaliação se constitui em elo, através do qual, se estabelece a relação qualitativa entre o que se pensou fazer, o que está sendo feito ou o que foi feito, criando as condições para se repensar o processo em sua plenitude ao considerar os seus resultados.

Assim, essa visão se ajusta com a ideia de Luckesi (2006), quando afirma que:

\footnotetext{
Enquanto o planejamento é o ato pelo qual decidimos o que construir, a avaliação é $O$ ato crítico que nos subsidia na verificação de como estamos construindo o nosso projeto. A avaliação atravessa 0 ato de planejar e de executar; por isso contribui em todo o percurso da ação planificada. A avaliação se faz presente não só na identificação da perspectiva político-social, como também na seleção de meios alternativos e na execução do projeto, tendo em vista a sua construção (LUCKESI, 2006, p. 126).
} 


\section{C

ISSN: 1984-6444 | http://dx.doi.org/10.5902/1984644438951

Tomando isso em conta, é importante destacar que a avaliação, tal como os objetivos, os conteúdos, os métodos, os meios de ensino e as formas de organização, é um dos componentes não pessoais do processo de ensino e aprendizagem que tem como elemento reitor os objetivos gerais e específicos que refletem o contexto social.

Nesta perspectiva, os objetivos de ensino expressam as intenções e as pretensões do que a sociedade, a escola e o professor anseiam. Assim, determinam, em grande medida, a seleção dos conteúdos, das habilidades, dos hábitos e atitudes que são contextualizados, sistematizados e dinamizados nos planos de aulas, cujas indicações sobre o seu cumprimento são proporcionadas por meio de avaliações de caráter holístico que se ajustam com as visões que são explicitadas no planejamento.

Portanto, a relação entre o planejamento docente e a avaliação se funda desde o cerne do imaginário da atuação do homem, caracterizando o seu passo a passo diante dos desafios que perpassam as áreas do saber que o motivam. Assim sendo, a avaliação para além de acompanhar a execução das atividades, também acompanha o planejamento, oferecendo as visões críticas, tanto a respeito dos intervenientes diretos, quanto do processo, da escola, do sistema educativo e do próprio governo, revelando a qualidade das suas opções políticas para com a escola.

\section{A avaliação vista na literatura e na realidade dos professores das escolas do I Ciclo em Cabinda: sua relação com a repetência escolar.}

Antes mesmo de se debruçar em torno da avaliação nos dois contextos, é importante lembrar-se que o professor avalia sempre que se propõe perceber se o que está sendo tratado na aula ou durante as aulas é ou foi entendido por todos os alunos da turma ao solicitar a opinião dos alunos sobre o assunto objeto da discussão. Neste sentido, a avaliação está presente em todos os momentos em que 
ISSN: 1984-6444 | http://dx.doi.org/10.5902/1984644438951

se estabelecem a relação entre o professor, o aluno e os conteúdos de ensino, numa abordagem contextualizada.

Assim sendo, as informações derivadas da utilização desse instrumento servem tanto para o professor avaliar-se a si próprio, a sua prática pedagógica, quanto a cognitividade, os hábitos e as atitudes formadas nos seus alunos, objetivando a melhoria da qualidade do processo de ensino e aprendizagem em benefício dos alunos.

$\mathrm{Na}$ mesma senda, Soca et al. (2007, p.67) entendem a avaliação como o componente que responde a pergunta: em que medida tem sido cumpridos os objetivos do processo de ensino e aprendizagem? Na visão dessas estudiosas, a avaliação joga um papel importante na regulação do processo de ensino e aprendizagem e é igualmente decisiva e fértil para a produção de novas visões na esfera da educação. Contudo, para essas autoras, a avaliação, paradoxalmente, é foco de desencantos em virtude do seu enraizamento no ensino de cunho tradicional e descontextualizado.

Tomando isso em conta, impõe-se considerar a década de 1980 como marco de destaque, referindo-se a utilidade desse instrumento. Nos meados dessa década, o conhecimento da escola e de suas práticas ganharam um novo fôlego, trazendo novas perspectivas de avaliação formativa, ancoradas em novas percepções sobre o fazer pedagógico dos professores (GOMES, 2014).

Segundo Dalben (1999) apud Gomes (2014), as novas visões pedagógicas que emergiram nessa década, para além do rompimento com o ensino assente na transmissão dos conhecimentos, advogavam por uma maior aproximação entre o professor, o aluno e o conhecimento, produzindo mudanças nos sentidos e significados sobre o processo de ensino e aprendizagem dos professores subjacente nos seus planos de aulas, assim como nas suas práticas avaliativas.

Com isso, a avaliação formativa, aquela que nasce do planejamento de aula ou da sequência didática, passa, por um lado, a considerar-se como categoria que perpassa, integralmente o processo de ensino e aprendizagem e os fatores que nele incidem. Por outro, passa a focar-se, privilegiando a instrução e a educação dos alunos, considerando o contexto e as particularidades das vivências de cada um dos 


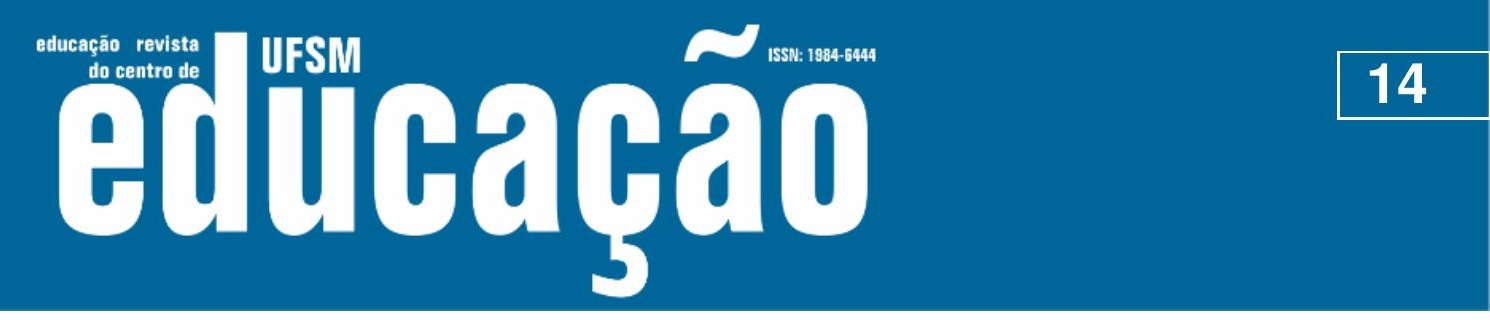

ISSN: 1984-6444 | http://dx.doi.org/10.5902/1984644438951

sujeitos do processo. Com isso, a incorporação da avaliação no dia a dia do professor como uma categoria essencial passa a ser uma exigência didática, assegurando a possibilidade de melhorar não apenas os conhecimentos do professor, mas também, o seu conhecimento para com o aluno e vice-versa.

Neste contexto, as estratégias do professor passam a ter como foco as possibilidades e as limitações dos seus alunos, na perspectiva de facilitar 0 desenvolvimento e a progressão de todo o coletivo de alunos, cada um consoante as suas particularidades. Desta feita, como aponta Gomes (2014), o professor passa a conhecer o retrato sociocultural do aluno, a sua situação econômica, suas percepções ante as atividades da sala de aula e da escola, seus sentimentos e suas expectativas.

Na visão dessa pesquisadora:

Um dos elementos fundamentais da concepção de educação e escola é a avaliação. Avaliar não significa classificar ou sentenciar, aprovar ou reprovar. Implica, isto sim, incidir sobre aspectos globais, do processo, a intervenção do professor, ao projeto, currículo da escola, a formação de identidades, dos valores (GOMES, 2014, p.39).

Assim, um processo de ensino e aprendizagem moldado num planejamento docente que privilegia a contextualização dos saberes, utilizando estratégias que encorajam a participação dos alunos, dando espaço para a manifestação de todas as suas qualidades, a avaliação reveste-se de uma natureza holística. Para além dos critérios estritamente cognitivos, surgem outros critérios mais, o qual anula o princípio da retenção do aluno ao incluir, entre outros critérios, aqueles que incidem na formação social do aluno (CORRÊA, 2000 apud GOMES, 2014).

$\mathrm{Na}$ essência dessa prática de avaliação se identifica vários critérios, que, em nosso ponto de vista, dimensionam o valor deste instrumento no processo de ensino e aprendizagem. Entre esses critérios, a título de exemplo, destacam-se: o nível de apropriação dos conteúdos disciplinares, fatuais, conceituais, procedimentais e atitudinais; o nível de participação do aluno nas atividades que decorrem na sala de aula e fora, em grupo e individualmente; a postura assumida pelo aluno nas atividades; a relação do aluno com o coletivo de alunos e professores; a assiduidade, o grau de independência e criatividade que o aluno manifesta nas 


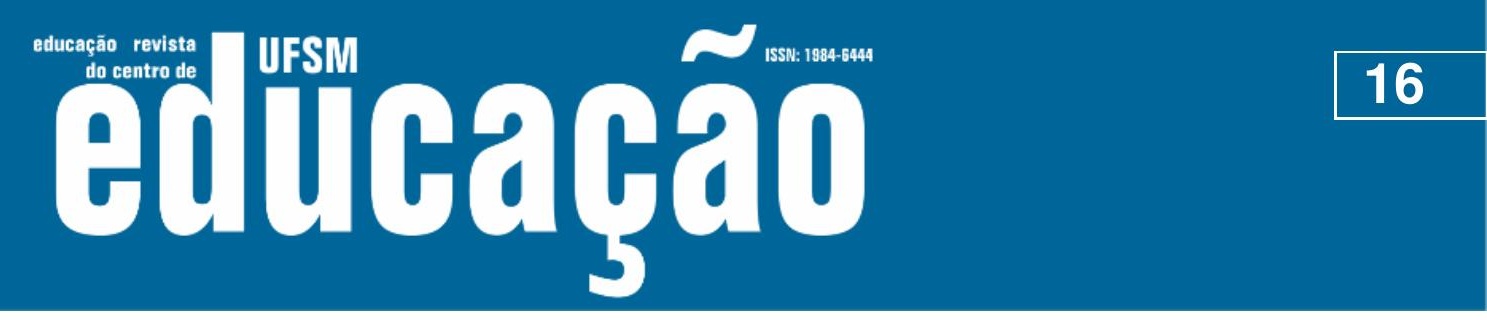

ISSN: 1984-6444 | http://dx.doi.org/10.5902/1984644438951

dia e trimestre é uma das condições essenciais para se aferir a condição final do aluno ao cabo de um trimestre ou um ano letivo, se reprova ou passa de classe, oscilando o seu valor de 1 a 5 , consoante a veracidade da resposta dada pelo aluno.

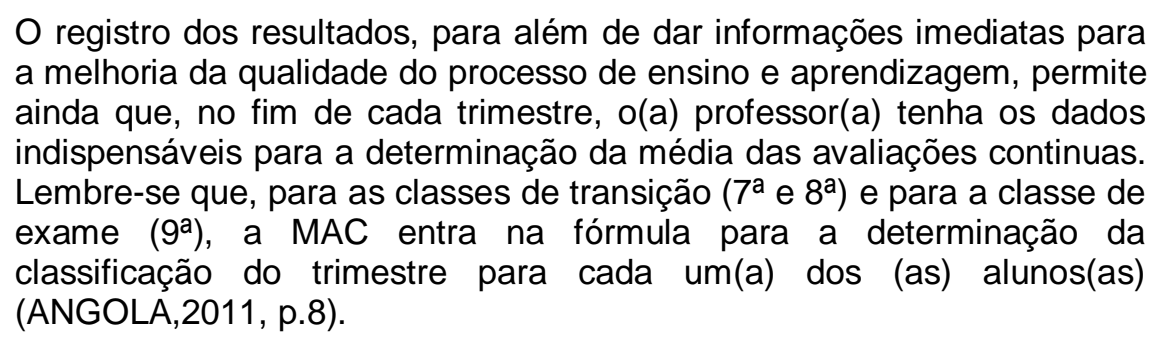

Com essas diretrizes, a média das avaliações contínuas de um aluno durante um trimestre obedece a aplicação da seguinte fórmula (ANGOLA, 2011, p.10): $M A C=\Sigma$ das médias de avaliação contínua durante o trimestre dividido pelo № total de avaliações.

Portanto, para a determinação da classificação do aluno em cada trimestre, faz-se a soma da média da avaliação contínua (MAC) com a classificação do aluno na prova do professor, somativa (CPP) e divide-se esse resultado por 2 , conforme mostra a fórmula:

$\mathrm{CT}_{1}=\mathrm{MAC}+\mathrm{CPP} / 2(1$ Trimestre $) ; \mathrm{CT}_{2}=\mathrm{MAC}+\mathrm{CPP} / 2(2$ Trimestre $)$ e $\mathrm{CT}_{3}=\mathrm{MAC}+\mathrm{CPP} / 2$ (3 Trimestre).

Quanto ao cálculo da CF (Classificação final do aluno), ANGOLA (2011) orienta a aplicação da seguinte fórmula:

$\mathrm{CF}=0,4 \times C A P+0,6 \times C P E$, onde CAP (Classificação atribuída pelo professor) é a média da somatória das provas somativas divididas por três, conforme se explicita na seguinte fórmula:

$\mathrm{CAP}=\mathrm{CT}_{1}+\mathrm{CT}_{2}+\mathrm{CT}_{3} / 3$

CPE (Classificação do aluno na Prova da Escola.

Contudo, segundo ANGOLA (2013), as três modalidades de avaliação, tanto na $7^{\text {a }}$, $8^{\text {a }}$ quanto na $9^{\text {a }}$ classe do I Ciclo, focam-se perspectivando obter os resultados que revelam o grau de cumprimento dos seguintes objetivos (ANGOLA, 2013):

- domínio das teorias, leis e princípios; 


\section{-

ISSN: 1984-6444 | http://dx.doi.org/10.5902/1984644438951

- grau de compreensão dos fenómenos abordados;

- capacidade de aplicar os conhecimentos adquiridos;

- capacidade de manusear os aparelhos e utensílios de laboratórios;

- capacidade de interpretar os fenómenos observados;

- capacidade de observação.

Um olhar às diretrizes que orientam os professores do I Ciclo do Ensino Secundários nas suas práticas avaliativas, nota-se que a expressão avaliação, a bem da verdade, é percebida como "formulação de juízo de valor e tomada de decisões na base de informações recolhidas sistematicamente" (ANGOLA, 2011, p.6), o qual, de uma forma ou de outra, coaduna com as visões que são identificadas na literatura (GOMES, 2014; DALBEN,1999).

No entanto, as diferentes formas de avaliação que são explicitadas nesses documentos, em particular, a formativa e a somativa, ao dar foco na atribuição de notas e na classificação dos alunos consoante os seus níveis de apropriação dos saberes disciplinares, aplicando fórmulas, as mesmas revelam contradições que não permitem conciliar o que dizem quando conceituam o termo avaliação e orientam que os professores façam ao avaliarem.

Esse modelo de avaliação parece sustentar-se numa abordagem de ensino e aprendizagem centrada nos aspetos cognitivos. Ou seja, os professores avaliam os conteúdos que ensinam, aqueles que por sua vez, constituem o foco de atenção nos documentos que lhes servem de apoio em suas práticas pedagógicas e avaliativas, colocando de lado o seu compromisso quanto a formação do homem novo.

Com essa visão, a avaliação para os professores do I Ciclo em Cabinda implica questionar os alunos e coletar informações que denotam o seu nível de apropriação dos saberes que fazem referência explícita aos conteúdos disciplinares dos seus programas, ajustando essas anotações às fórmulas que expressam as visões que são defendidas nesses documentos, tendo em vista os seus objetivos.

Desta feita, essa prática avaliativa parece ajustar-se ao ensino tradicional, no qual, os objetivos disciplinares (instrutivos) ao nortearem a elaboração e a execução dos planos de aula e da avaliação, os mesmos concorrem para a determinação do 


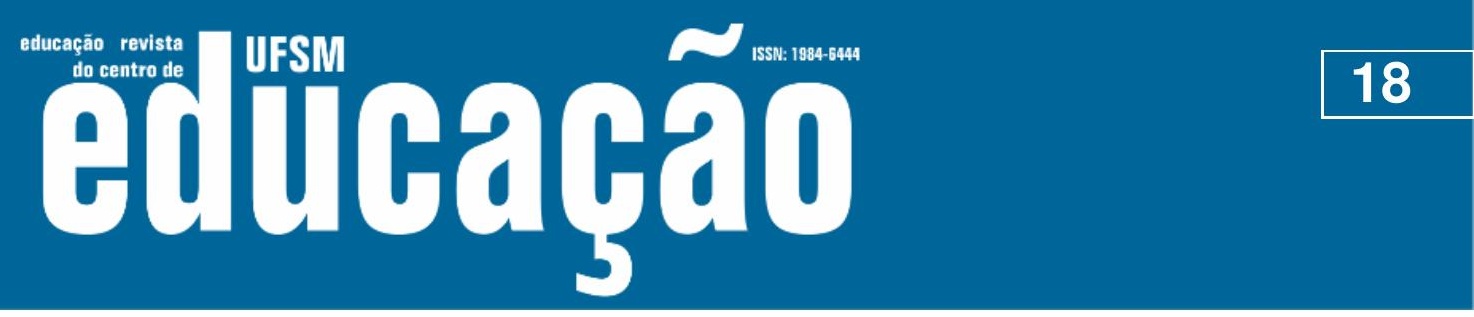

ISSN: 1984-6444 | http://dx.doi.org/10.5902/1984644438951

destino final do aluno, onde por regra, a repetência surge como uma expressão vulgar, reservada para os alunos que mostram um aparente aproveitamento insatisfatório nesses quesitos.

Tomando isso em conta, vale aqui lembrar que a repetência escolar, atualmente, tem sido apontada como um dos problemas que enfermam a qualidade do processo de ensino e aprendizagem das escolas do I e II Ciclo em Cabinda (MAVUNGO, 2014; MUELAS, 2018), entre outros.

No trabalho de Mavungo (2014), que envolveu mais de 103 alunos da 9a classe, de uma escola do I Ciclo na cidade de Cabinda, esse problema de forma concisa foi identificado, trazendo à tona o histórico escolar dos mesmos, conforme se apresenta seguidamente na tabela 1.

Tabela 1- Histórico escolar dos alunos da 9ª classe da Escola do I Ciclo de Cabassango.

\begin{tabular}{|c|c|c|}
\hline $\begin{array}{c}\mathbf{N}^{\circ} \text {. vezes em que } \\
\text { o aluno reprovou } \\
\text { de classe }\end{array}$ & $\mathbf{N}^{\circ}$. de Alunos & Percentagens \\
\hline Nunca & 15 & $14.85 \%$ \\
\hline Uma Vez & 52 & $51.48 \%$ \\
\hline Duas Vezes & 21 & $20.79 \%$ \\
\hline Três Vezes & 9 & $8.91 \%$ \\
\hline Quatro vezes & 1 & $0.99 \%$ \\
\hline Cinco Vezes & 2 & $1.98 \%$ \\
\hline Seis Vezes & 1 & 0.99 \\
\hline
\end{tabular}

Fonte: Mavungo (2014)

Vale salientar que a repetência escolar embora tradicionalmente é conhecida como um problema que deriva do aluno, a verdade é que se analisarmos a natureza 


\section{TIFSM \\ ISSN: $1984-6444$

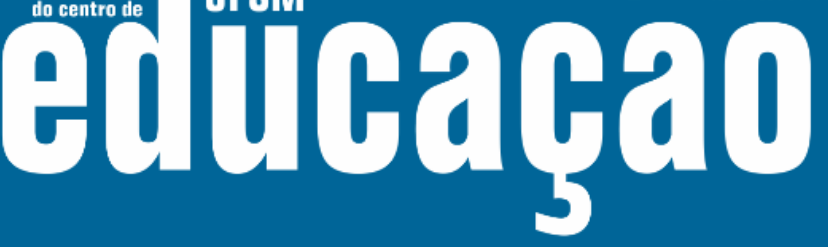

ISSN: 1984-6444 | http://dx.doi.org/10.5902/1984644438951

e a qualidade dos planos de aulas, isto é, o trabalho de planejamento docente, assim como as bases que norteiam o sistema de avaliação que é utilizado, é possível se enxergar uma boa parte das verdadeiras causas que estão na base desse problema de grande impacto social.

Essa visão sustenta-se quando reconhecemos que o planejamento docente e a avaliação desvinculados da realidade social e das particularidades dos alunos constituem-se em instrumentos que ao invés de liderarem a todos ou a grande maioria dos alunos para o sucesso, à progressão, traduzem-se em vectores da repetência escolar, fruto das escolhas incoerentes do professor, da escola e do governo, como autor das políticas públicas educativas do país.

Portanto, um sistema educativo que tem a escola como um espaço onde são oferecidos benefícios e possibilidades para todos os que nela acessam, crianças, jovens e adultos, a revitalização da sua qualidade passa necessariamente por diferentes trilhos, mas que, confluem e convergem no mesmo ponto, favorecendo a formação do homem novo, dotado das capacidades que garantem a sua afirmação social.

Nesta perspectiva, um desses trilhos passa por uma reflexão crítica em torno do planejamento docente dos professores. Aquele planejamento comprometido com a qualidade, a atenção à diversidade, as particularidades, as dificuldades, a realidade. É pertinente e atuante se pensar num trabalho diário do professor que tenha como elemento condutor um planejamento docente com visões sociais alargadas e de maior alcance, contextualizado com as realidades vividas pelos sujeitos do processo, em particular, aqueles com história de repetência, reconhecendo os seus saberes.

Atuando assim, a avaliação do professor surgirá alicerçada nas percepções que sustentam o seu próprio planejamento docente, convertendo esse instrumento em alavanca de mudança, revelador das apostas do professor, a sua forma de ver a educação, a escola e à docência, engajando-se em prol dos desafios que são enfrentados pelos alunos, pela escola, pela sociedade e pelo país.

Enfim, a ausência destes pressupostos nas escolas do I Ciclo do ensino secundário em Angola configura-se em autênticas condições que agravam os 


\section{N

ISSN: 1984-6444 | http://dx.doi.org/10.5902/1984644438951

índices de repetência e o abandono escolar dos alunos, fato esse que se ramifica, potenciando a pobreza, as descriminações, a injustiça e as desigualdades sociais entre os cidadãos.

Diante disso, pensar numa avaliação como recurso a favor da progressão do aluno que se consubstancia num planejamento pautado nas finalidades políticas e sociais remete-nos a visão da professora Gomes (2014), quando defende que uma avaliação revestida da sua natureza qualitativa e processual se constitui por meio de conceitos registrados que retratam o decorrer do processo de ensino e aprendizagem, através de observações atentas as mais diversas intervenções e atitudes que o aluno expressa durante a(s) aula(s).

Nessa visão, exclui-se em passar a ideia de que a escola e o professor, a toda custa, deixem aprovar a todos os alunos da turma sem esforços tanto do aluno quanto do professor. Os desafios que são lançados aos professores nesse entendimento, enquadram-se na necessidade de repensarem melhor o seu fazer pedagógico em sua totalidade, em particular, o seu planejamento docente e a avaliação, no sentido de incorporarem o debate, as discussões e a problematização dos conteúdos, objetos da aprendizagem dos alunos e na solução de problemas.

\section{Conclusões}

Este estudo ao lançar-se em torno do que é dito na literatura, nos documentos oficiais, referindo-se ao planejamento docente, a avaliação e a repetência escolar, o mesmo tinha em perspectiva oferecer uma reflexão sobre como esses processos são vividos pelos professores e alunos das escolas do I Ciclo em Cabinda, tenha vista as vozes dissonantes que se fazem ouvir na sociedade angola, tratando-se do papel da escola.

O levantamento bibliográfico feito aponta que existe profundas divergências entre as explicitações que são oferecidas na literatura (HAIDT, 2004; LUCKESI, 2006; LIBÂNEO, 1994; GOMES, 2014; FREIRE, 1996; MAVUNGO, 2014), e as diretrizes contidas nos documentos oficiais (ANGOLA, 2011, 2012, 2013), que 
orientam o fazer pedagógico dos professores tanto na elaboração dos planos de aulas quanto na avaliação aos alunos.

Em face disso, as análises feitas permitiram perceber-se que os trabalhos de planejamento diários dos professores podem ser uma das razões que estão por detrás dos maus resultados que são lidos e observados, apontando as reprovações dos alunos nas escolas do I Ciclo em Cabinda.

Nesta perspectiva, é de realçar que tanto a elaboração dos planos de aulas quanto dos instrumentos de avaliação exige-se do professor a mobilização do seu sistema de saberes, em particular, os saberes disciplinares e didáticos. Outrossim, também se exige do professor um profundo conhecimento do contexto social e cultural no qual se encontram inseridos os sujeitos do seu processo educativo.

Neste contexto, o professor deve, no seu fazer pedagógico planejado, vincular os conteúdos que são objeto das discussões e debates à realidade do contexto vivido pelos alunos, diversificando as formas de abordagem dos mesmos, particularizando as intervenções dos alunos, cada um consoante as suas possibilidades e limitações, humanizando a sua atuação na mediação do processo da construção dos saberes.

Com isso, o professor deverá valorizar a atuação de cada um dos seus alunos, dando-Ihes as indicações pertinentes que os sirvam de encorajamento para a superação das suas lacunas. Para o efeito, deve colocar em mesmos patamares tanto a aquisição de conhecimentos científicos quanto a formação e o desenvolvimento de capacidades, atitudes e hábitos socialmente valiosos, indispensáveis na formação da personalidade do aluno e na formação de uma sociedade mais justa.

Com isso, é de salientar que as visões que são explicitadas nos planejamentos diários percorrem todo processo educativo, qual astro errante, tornando-se visíveis, perceptíveis por meio das avaliações, cujos resultados expressos em números ou letras mostram o retrato do professor, da qualidade das suas opções pedagógicas e da escola.

Tendo isso em conta, neste estudo concluiu-se que a qualidade do planejamento diário dos professores tem reflexos nos resultados das avaliações dos 


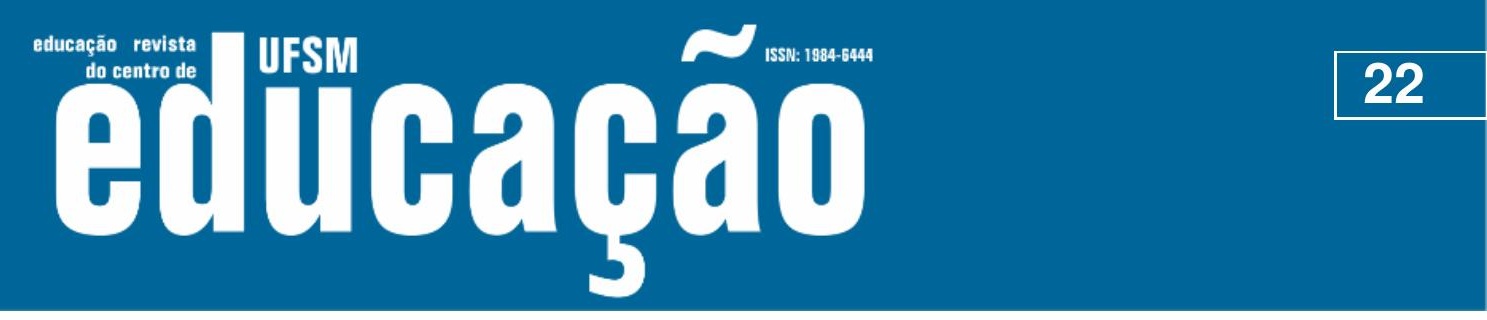

ISSN: 1984-6444 | http://dx.doi.org/10.5902/1984644438951

alunos e incidem nos índices de repetência escolar que são observados nas escolas do I Ciclo em Cabinda.

Enfim, uma solução para a mudança deste quadro parece passar, necessariamente, por um processo de construção e reconstrução de saberes por parte dos professores, gestores escolares e dos fazedores de políticas públicas, o estado, buscando ressignificar o papel da escola diante da sociedade, cujo desnorte tem se tornado evidente à luz dos altos índices de repetência e do abandono escolar que são observados quase que em todo sistema educativo angolano.

\section{Referências}

ANGOLA. Caderneta do Professor 1. ${ }^{\circ}$ Ciclo Ensino Secundário. Luanda: Editora Moderna, 2012.

ANGOLA. Manual de apoio ao sistema de avaliação das aprendizagens. $1 .^{\circ}$ Ciclo do Ensino Secundário. Luanda: Inide, 2011.

ANGOLA. Programa de Biologia de 7ª, $8^{a}$ e $9^{a}$ classes. Luanda: Editora Moderna, 2013.

ANGROSINO, Michael. Etnografia e Observação Participante. Porto Alegre: Artmed, 2009.

CORRÊA, Maria Letitia. Não-retenção e relações de poder: ponto focal de resistência ao Projeto Escola Plural. In: DALBEN, Angela Imaculada Loureiro de Freitas (Org.). Singular ou plural? Eis a questão. Belo Horizonte: GAME/FAE/UFMG, 2000, p.91-110.

DALBEN, Angela Imaculada Loureiro de Freitas. Avaliação escolar e a relação com o conhecimento. Caderno de Educação, Belo Horizonte, p. 74-87, 1999.

DELORS, Jacques. La educación encierra un tesoro. Informe de la UNESCO a la comisión internacional sobre la educación para el Siglo XXI. Madrid: Santillana Ediciones Unesco, 1996.

FREIRE, Paulo. Pedagogia da autonomia: saberes necessários à prática educativa. São Paulo. Paz e Terra, 1996.

GOMES, Suzana dos Santos. Um olhar sobre as práticas de avaliação na escola. Belo Horizonte: Mazza edições, 2014.

HAIDT, Regina Célia Cazaux. Curso de Didática Geral. São Paulo: Editora ática, 2004.

HOLANDA, Nilson. Planejamento e projetos. Rio de Janeiro: Editora APEC, 1977. 


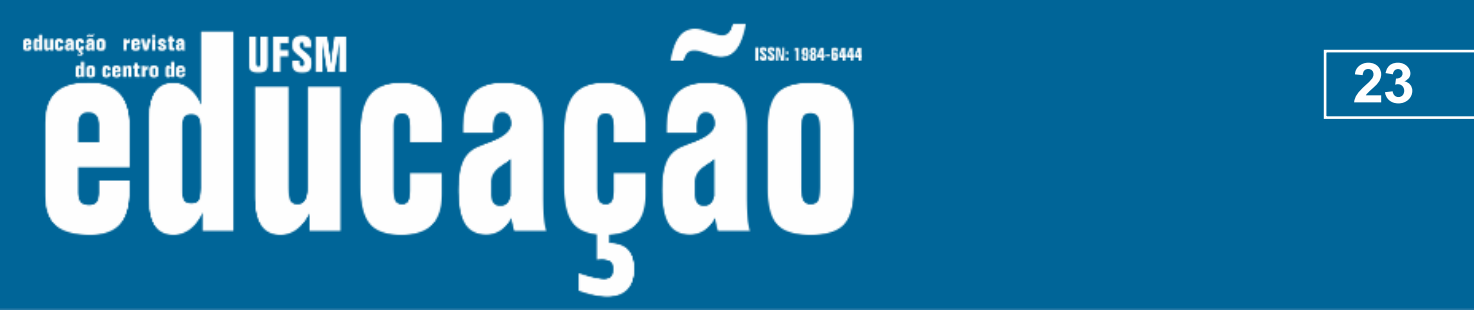

ISSN: 1984-6444 | http://dx.doi.org/10.5902/1984644438951

LIBÂNEO, José Carlos. Didática. São Paulo: Editora Cortez, 1994.

LUCKESI, Cipriano Carlos. Planejamento e Avaliação na Escola: articulação e necessária determinação ideológica. Série Idéias, n. 15. São Paulo: FDE, 2006.

MAVUNGO, Fernando Abel. Estratégias metodológicas utilizadas pelos professores de biologia no âmbito do trabalho independente. Um estudo na Escola do I Ciclo de Cabassango. Dissertação (Mestrado)- Faculdade da Educação da Universidade Federal de Minas Gerais, Belo Horizonte: 2014.

PIUAí (Estado). Secretaria do Estado da Educação e Cultura. Diretrizes da Rede Pública Estadual de Ensino de Piauí, Teresina: SEDUC, 2013.Disponível em: https://www.seduc.pi.gov.br/arquivos/diretrizes/1Diretrizes_Curriculares_da_Educaca o_Basica_SEDUC_PI.pdf. Acesso em: 20 jan. 2019.

SOCA, Ana Maria González; FERNÁNDEZ, Silvia Recarey; FERNÁNDEZ, Fátima Addine. La dinámica del proceso de enseñanza-aprendizaje mediante sus componentes.In: FERNÁNDEZ, Fátima Addine. (org.). Didáctica: teoria y práctica. 2. ed. Ciudad de la Habana: Plueblo y educacion, 2007. p. 56-74.

TURRA, Clódia Maria Godoy et al. Planejamento de ensino e avaliação. Porto Alegre: Editora Emma, 1975, p.11-21.

\section{Correspondência}

Fernando Abel Mavungo - Universidade 11 de Novembro - República de Angola, Região Académica III, Cabinda, Zaire.

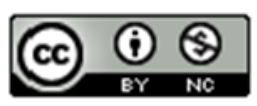

This work is licensed under a Creative Commons Attribution-NonCommercial 4.0 International (CC BY-NC 4.0) 